\title{
Taxane Chemotherapy for Hormone-Naïve Prostate Cancer with Its Expanding Role as Breakthrough Strategy
}

\author{
Masaki Shiota*, Akira Yokomizo and Masatoshi Eto \\ Department of Urology, Graduate School of Medical Sciences, Kyushu University, Fukuoka, Japan
}

\section{OPEN ACCESS}

Edited by:

Camillo Porta,

IRCCS San Matteo University

Hospital Foundation, Italy

Reviewed by:

Giuseppe Procopio,

Fondazione IRCCS Istituto

Nazionale Tumori, Italy

Takeo Kosaka,

Keio University School of

Medicine, Japan

*Correspondence: Masaki Shiota

shiota@uro.med.kyushu-u.ac.jp

Specialty section: This article was submitted to Genitourinary Oncology, a section of the journal

Frontiers in Oncology

Received: 04 November 2015 Accepted: 18 December 2015

Published: 11 January 2016

Citation:

Shiota $M$, Yokomizo $A$ and Eto $M$ (2016) Taxane Chemotherapy for Hormone-Naive Prostate Cancer with Its Expanding Role as

Breakthrough Strategy.

Front. Oncol. 5:304.

doi: 10.3389/fonc.2015.00304
Historically, androgen-deprivation therapy (ADT) was the only primary treatment for metastatic prostate cancer. After prostate cancer develops into castration-resistant prostate cancer (CRPC), there are a few life-prolonging drugs, including taxanes, such as docetaxel and cabazitaxel, as well as novel androgen receptor-targeting agents, such as abiraterone acetate and enzalutamide, which have been proved in clinical trials. However, the prognosis of men with CRPC is still poor. The duration from initiation of ADT to CRPC has not improved in recent decades because no novel therapeutic options have emerged. However, recently, up-front docetaxel chemotherapy has been shown to prolong progression-free as well as overall survival in men with metastatic hormone-naive prostate cancer. This offers a new way to expand the role of chemotherapy for hormone-naive prostate cancer. In this review, we summarize the proof-of-concept as well as the current status of taxane chemotherapy for hormone-naïve prostate cancer, focusing on phase 3 clinical trials investigating oncological outcome, and discuss the future direction in this field.

Keywords: androgen-deprivation therapy, cabazitaxel, castration-resistant prostate cancer, docetaxel, hormonenaïve prostate cancer

\section{INTRODUCTION}

Previously, hormonal therapy such as androgen-deprivation therapy (ADT) using surgical or pharmacological castration and/or antiandrogens was the only gold standard for therapy of metastatic prostate cancer. However, historically, the efficacy of ADT was limited, and most prostate cancer developed into castration-resistant prostate cancer (CRPC) in about 2 years. When prostate cancer developed into CRPC, until 2004, there were no life-prolonging drugs that had been proved by clinical trial, and prognosis of men with CRPC was poor. However, in 2004, docetaxel chemotherapy was shown to prolong survival of men with metastatic CRPC $(1,2)$ and has become standard therapy for metastatic CRPC. Since 2010, in addition to the immunotherapeutic agent sipuleucel-T and radiopharmaceutical Ra-223, three agents for metastatic CRPC, including novel androgen receptor (AR)-targeting agents abiraterone acetate and enzalutamide, as well as novel taxane cabazitaxel, have been shown to prolong overall survival (OS) (3). Accordingly, those agents have been approved by the relevant authorities in many countries. Thus, the prognosis of men with metastatic CRPC was improved by those novel agents. However, the time to CRPC was 
not improved where policy dictated that only ADT should be administered and no additional therapy was considered.

Recently, some important clinical trials investigating the role of docetaxel chemotherapy for metastatic hormone-naïve prostate cancer have been reported. In this review, we summarize the proof-of-concept and the current status of chemotherapy for hormone-naïve prostate cancer, focusing on phase 3 clinical trials investigating oncological outcome, and discuss the future direction in this field.

\section{PROOF-OF-CONCEPT BY BASIC RESEARCH}

Although chemotherapy has been the gold standard for metastatic disease in various types of cancer, there was no life-prolonging chemotherapy for prostate cancer until 2004. However, since the emergence of docetaxel chemotherapy for metastatic CRPC in $2004(1,2)$, the hypothesis that docetaxel chemotherapy may be effective also for hormone-naïve prostate cancer was generated. Accordingly, basic research has been conducted to examine the proof-of-concept.

In 2005, Eigl et al. compared tumor growth in three groups of mice bearing Shionogi and LNCaP xenografts treated with (i) initial castration and delayed paclitaxel; (ii) initial paclitaxel and delayed castration; or (iii) simultaneous castration plus paclitaxel (4). Simultaneous ADT plus paclitaxel was more effective than sequential treatment by initial castration and delayed paclitaxel in both xenograft models (4), although there was no difference in an MDA PCa2b xenograft model (5). In line with this notion, we have recently shown cross-resistance to docetaxel in CRPC cells, but not vice versa using an LNCaP cell model (6). Thus, these results provide proof-of-concept for possible superior anticancer activity of up-front taxane chemotherapy for hormone-naïve prostate cancer, compared with traditional ADT followed by docetaxel chemotherapy.

Several studies have examined whether metastatic status affects the efficacy of taxane chemotherapy. Marín-Aguilera et al. reported that gene expression related to epithelial-mesenchymal transition was altered in radical prostatectomy specimens when treated with neoadjuvant docetaxel chemotherapy, and correlated with relapse (7). Also, mesenchymal marker expression was upregulated in docetaxel-resistant cells, in which knockdown of mesenchymal marker ZEB1 reversed docetaxel resistance (7). By contrast, the expression of epithelial marker E-cadherin was downregulated in docetaxel-resistant cells (8). These results suggest docetaxel resistance in highly metastatic prostate cancer with a high level of epithelial-mesenchymal transition, supporting the superior anticancer effect of docetaxel chemotherapy for non-metastatic hormone-naïve prostate cancer compared with metastatic prostate cancer.

\section{METASTATIC HORMONE-NAÏVE PROSTATE CANCER}

The results of the French GETUG-AFU-15 study were reported in 2013. It did not show any improvement of OS by combining docetaxel chemotherapy with ADT for metastatic hormone-naïve prostate cancer, although docetaxel chemotherapy did improve progression-free survival (PFS) (9). The results failed to overcome the traditional concept that ADT is only useful for metastatic hormone-naïve prostate cancer. However, in 2015, the CHAARTED study conducted by the Eastern Cooperative Oncology Group investigating the utility of up-front docetaxel chemotherapy for metastatic hormone-naïve prostate cancer showed improved PFS as well as OS (10). Furthermore, the STAMPEDE trial in the UK also reported that both PFS and OS were improved by docetaxel chemotherapy in addition to ADT (11). Thus, one study failed, but two others showed significant improvement with up-front docetaxel administration for metastatic hormone-naïve prostate cancer, although all three studies were conducted with similar concept and design.

Why did those trials report controversial results? Although there seems to be several differences among those clinical trials, such as (i) the number of docetaxel cycles, (ii) sample size, (iii) proportion of high-volume disease, (iv) length of follow-up, and (v) unignorable chemotherapy-related mortality (12, 13), we suggest that the most significant difference was the subsequent treatments after progression to CRPC. At the time when the GETUG-AFU-15 trial was conducted, most novel therapeutics against CRPC were under development. Then, only a few patients were treated with cabazitaxel and only a small number of patients were recruited to clinical trials using abiraterone acetate and enzalutamide (Table 1). In contrast, the CHAARTED and STAMPEDE trials were both conducted in era of novel therapeutics for CRPC. In the CHAARTED trial, cabazitaxel was utilized more frequently (24 vs. $13 \%)$ as were abiraterone acetate and enzalutamide ( 44 vs. $36 \%$ ), in the ADT plus docetaxel group compared with the ADT monotherapy group, although docetaxel rechallenge was less frequent (23 vs. $48 \%$ ) (Table 1). Similarly, in the STAMPEDE trial, cabazitaxel was utilized more frequently (6 vs. $3 \%$ ) as were abiraterone acetate and enzalutamide (35 vs. $30 \%$ ) in the ADT plus docetaxel group, although docetaxel rechallenge was less (14 vs. $41 \%$ ) (Table 1). Collectively, if there was no survival-prolonging agent, there may be no difference between up-front and delayed docetaxel use. However, now we can utilize several novel life-prolonging agents against CRPC, even in a postdocetaxel setting, which can be administered sequentially after up-front docetaxel chemotherapy. It has recently been reported that only $4.4 \%$ of CRPC patients in the US received AR-targeting agents and cabazitaxel in addition to docetaxel chemotherapy (14); therefore, achieving sufficient use of therapeutics for CRPC would be difficult, which may compromise the merit of novel agents.

Up-front docetaxel chemotherapy is effective against hormone-naïve prostate cancer, as demonstrated by a recently published meta-analysis (13). Cabazitaxel chemotherapy is also active against prostate cancer, with evidence of improved OS among men with metastatic CRPC (15). The FIRSTANA study (NCT01308567) is now examining oncological outcome of docetaxel and cabazitaxel as first-line chemotherapy for metastatic CRPC. Therefore, up-front cabazitaxel 
TABLE 1 | Subsequent active therapy after progression to CRPC.

\begin{tabular}{|c|c|c|c|c|c|c|}
\hline \multirow{2}{*}{$\begin{array}{l}\text { Study } \\
\text { Arm }\end{array}$} & \multicolumn{2}{|c|}{ GETUG-AFU-15 } & \multicolumn{2}{|c|}{ CHAARTED } & \multicolumn{2}{|l|}{ STAMPEDE } \\
\hline & ADT plus docetaxel & ADT & ADT plus docetaxel & ADT & ADT plus docetaxel & ADT \\
\hline The number of enrolled cases, $n$ & 192 & 193 & 397 & 393 & 592 & 1184 \\
\hline The number of cases progressed to CRPC, $n$ & NA & NA & 238 & 287 & 311 & 750 \\
\hline \multicolumn{7}{|l|}{ Chemotherapy } \\
\hline Docetaxel & 54 & 120 & 54 (23\%) & $137(48 \%)$ & $14 \%$ & $41 \%$ \\
\hline Cabazitaxel & 3 & 2 & $57(24 \%)$ & 37 (13\%) & $6 \%$ & $3 \%$ \\
\hline \multicolumn{7}{|l|}{ AR-targeting agent } \\
\hline Abiraterone acetate & $16^{a}$ & $29^{a}$ & $105(44 \%)$ & $104(36 \%)$ & $28 \%$ & $23 \%$ \\
\hline Enzalutamide & & & & & $7 \%$ & $7 \%$ \\
\hline Orteronel & & & NA & NA & NA & NA \\
\hline \multicolumn{7}{|l|}{ Others } \\
\hline Sipuleucel-T & NA & NA & $22(9 \%)$ & $19(5 \%)$ & NA & NA \\
\hline Ra-223 & NA & NA & NA & NA & $1 \%$ & $0 \%$ \\
\hline
\end{tabular}

${ }^{a}$ Referred from Ref. (12).

NA, not available; percentage number represent the proportion among cases progressed to CRPC.

TABLE 2 | Phase 3 clinical trials examining taxane chemotherapy for hormone-naïve prostate cancer.

\begin{tabular}{|c|c|c|c|c|c|c|c|}
\hline Study & Identifier & Organizer & Taxane & Stage & Control arm & $\begin{array}{l}\text { Primary } \\
\text { endpoint }\end{array}$ & Result \\
\hline GETUG-AFU-15 & NCT00104715 & GETUG-AFU (French) & Docetaxel & Metastatic & ADT & OS, PFS & Negative \\
\hline CHAARTED & NCT00309985 & ECOG (US) & Docetaxel & Metastatic & ADT & OS & Positive \\
\hline STAMPEDE & NCT00268476 & $\begin{array}{l}\text { Medical Research } \\
\text { Council (UK) }\end{array}$ & Docetaxel & Metastatic & ADT & OS & Positive \\
\hline SensiCab & NCT01978873 & $\begin{array}{l}\text { Örebro University } \\
\text { (Sweden) }\end{array}$ & Cabazitaxel & Metastatic & ADT & OS & NA \\
\hline SPCG 12 & NCT00376792 & SPCG & Docetaxel & Non-metastatic & $\mathrm{RP}$ (adjuvant) & PFS & NA \\
\hline 553 & NCT00132301 & $\begin{array}{l}\text { Department of Veterans } \\
\text { Affairs (US) }\end{array}$ & Docetaxel & Non-metastatic & RP (adjuvant) & PFS & NA \\
\hline CALGB 90203 & NCT00430183 & CALGB (US) & Docetaxel & Non-metastatic & $\begin{array}{l}\text { RP with } \\
\text { neoadjuvant ADT }\end{array}$ & PFS & NA \\
\hline XRP6976J 3501 & NCT00283062 & Sanofi & Docetaxel & Non-metastatic & $\begin{array}{l}\text { RP with adjuvant } \\
\text { vs. salvage ADT }\end{array}$ & PFS & $\begin{array}{l}\text { Early terminated with } \\
\text { negative result }\end{array}$ \\
\hline RTOG-9902 & NCT00004054 & RTOG (US) & Paclitaxel & Non-metastatic & RT with ADT & OS & Negative \\
\hline GETUG 12 & NCT00055731 & GETUG (French) & Docetaxel & Non-metastatic & $\begin{array}{l}\text { RT (or RP) with } \\
\text { adjuvant ADT }\end{array}$ & PFS & Improved PFS \\
\hline RTOG-0521 & NCT00288080 & RTOG (US) & Docetaxel & Non-metastatic & RT with ADT & OS & Improved OS \\
\hline SPCG 13 & NCT00653848 & SPCG & Docetaxel & Non-metastatic & RT with ADT & PFS & NA \\
\hline 05-043 & NCT00116142 & $\begin{array}{l}\text { Dana-Farber Cancer } \\
\text { Institute (US) }\end{array}$ & Docetaxel & Non-metastatic & RT with ADT & OS & NA \\
\hline DART & NCT00651326 & $\begin{array}{l}\text { NCIC Clinical Trials } \\
\text { Group (Canada) }\end{array}$ & Docetaxel & Non-metastatic & RT with ADT & PFS & NA \\
\hline PEACE2 & NCT01952223 & $\begin{array}{l}\text { Collaborative European } \\
\text { Group }\end{array}$ & Cabazitaxel & Non-metastatic & $\begin{array}{l}\text { Prostatic vs. pelvic } \\
\text { RT with ADT }\end{array}$ & PFS & NA \\
\hline SPCG 14 & - & SPCG & Docetaxel & $\begin{array}{l}\text { Non-metastatic, PSA } \\
\text { recurrence after RP or RT }\end{array}$ & Bicalutamide & PFS & NA \\
\hline RTOG-P-0014 & NCT00030654 & RTOG (US) & Docetaxel & $\begin{array}{l}\text { Non-metastatic, PSA } \\
\text { recurrence after RP or RT }\end{array}$ & Various & OS & NA \\
\hline XRP6976J 3503 & NCT00514917 & Sanofi & Docetaxel & $\begin{array}{l}\text { Non-metastatic, PSA } \\
\text { recurrence after RP or RT }\end{array}$ & ADT & PFS & $\begin{array}{l}\text { Early terminated with } \\
\text { marginal result }\end{array}$ \\
\hline
\end{tabular}

OS, overall survival; PFS, progression-free survival; RP, radical prostatectomy; $R T$, radiotherapy.

chemotherapy combined with standard ADT can also be effective for metastatic hormone-naïve prostate cancer, which has been examined by the Swedish clinical trial SensiCab
(NCT01978873, Table 2). A clinical trial comparing up-front docetaxel and cabazitaxel chemotherapy combined with ADT would be intriguing. 


\section{NON-METASTATIC HORMONE-NAÏVE PROSTATE CANCER}

In addition to the promising role of taxane chemotherapy for metastatic hormone-naive prostate cancer, there may be the possibility of efficacy for non-metastatic hormone-naïve prostate cancer. This is supported by the basic research discussed above, as well as non-randomized clinical studies showing feasibility and modest efficacy. Accordingly, several phase 3 clinical studies have been under investigation (16).

\section{Taxane Chemotherapy with Surgical Therapy}

Radical prostatectomy for localized prostate cancer is the standard curative therapy and shows excellent oncological outcome. However, there is a high recurrence rate in high-risk patients, who are defined as high stage, high Gleason score, and high prostatespecific antigen (PSA) level at diagnosis. To improve the outcome of high-risk localized prostate cancer, the Southwest Oncology Group explored the role of mitoxantrone chemotherapy after radical prostatectomy in oncological outcome in a phase 3 clinical trial of 983 patients (SWOG S9921, NCT00004124). They failed to show significant improvement of PFS as primary endpoint (17), although mitoxantrone was palliative but not life-prolonging for men with CRPC. However, because docetaxel has been shown to be active against prostate cancer, various studies using docetaxel chemotherapy have been conducted and are in progress (Table 2) (18). The Scandinavian Prostate Cancer Group (SPCG) group has been examining whether adjuvant docetaxel for high-risk prostate cancer after radical prostatectomy can improve outcome (SPCG 12, NCT00376792). A similarly designed phase 3 trial (NCT00132301) is also ongoing in the US. A phase 3 study by the Cancer and Leukemia Group B (CALGB 90203, NCT00430183) is comparing oncological outcome after radical prostatectomy with or without neoadjuvant docetaxel chemotherapy plus ADT in 750 randomized patients with high-risk prostate cancer. So far, only one study (XRP6976J_3501, NCT00283062) has been terminated early because of poor recruitment of patients. The study was examining immediate treatment following prostatectomy vs. deferred treatment at the time of relapse with docetaxel plus ADT vs. ADT alone.

\section{Taxane Chemotherapy with Radiotherapy}

Similarly to surgical therapy, oncological outcome of radiotherapy for high-risk prostate cancer has been modest. Although combination with $\mathrm{ADT}$ can improve the outcome, the improvement is far from satisfactory, and further improvement has to be pursued. The Radiation Therapy Oncology Group (RTOG) has explored the role of chemotherapy with paclitaxel, estramustine, and etoposide combined with radiotherapy and long-term ADT in a phase 3 clinical trial of 397 patients (RTOG-9902, NCT00004054). They failed to show significant improvement of OS as primary endpoint (19), although paclitaxel has never been shown to be active in prostate cancer treatment. Several clinical trials have examined the effect of active taxane chemotherapy, such as docetaxel and cabazitaxel, combined with radiotherapy as shown below and in Table 2 . The
GETUG 12 trial (NCT00055731) showed improved PSA decrease at 3 months, as well as improved relapse-free survival of neoadjuvant docetaxel and estramustine chemotherapy, in addition to ADT plus local therapy, mostly with definitive radiotherapy for high-risk localized prostate cancer $(20,21)$. Consistently, RTOG (RTOG-0521, NCT00288080) has recently reported improved OS of docetaxel chemotherapy, in addition to ADT plus radiotherapy (22). Thus, two randomized trials have recently shown superior prognosis with docetaxel chemotherapy combined with radiotherapy. In addition, The SPCG group has been investigating whether adjuvant docetaxel for high-risk prostate cancer after radiotherapy combined with ADT improves outcome (SPCG 13, NCT00653848) (23). They reported that toxicity in patients receiving adjuvant docetaxel was well tolerated although frequency of neutropenia was higher, but PFS as primary endpoint has not been reached. Similarly, they Dana-Farber Cancer Institute (NCT00116142) and a Canadian group (DART, NCT00651326) have been conducting phase 3 clinical trials examining whether docetaxel improves outcome after radiotherapy combined with ADT in patients with high-risk localized prostate cancer.

The novel taxane cabazitaxel is also under investigation. A European collaborative group has been conducting a phase 3 trial in patients with localized prostate cancer with high risk of relapse (PEACE2, NCT01952223), comparing $\mathrm{ADT}+$ prostate radiotherapy, $\mathrm{ADT}+$ pelvic radiotherapy, cabazitaxel + ADT + prostate radiotherapy, and cabazitaxel + ADT + pelvic radiotherapy.

\section{Taxane Chemotherapy for Non-Metastatic Recurrent Disease}

For biochemical recurrent non-metastatic disease after radical prostatectomy or radiotherapy, $\mathrm{ADT}$ has been the primary standard therapeutic option. However, most recur in a castrationresistant fashion, requiring improvement of management of such patients.

Accordingly, the SPCG group has been conducting a phase 3 clinical trial (SPCG 14) to examine whether additional docetaxel chemotherapy improves the outcome when combined with standard ADT. Similarly, the RTOG group has been conducting a phase 3 trial (RTOG-P-0014, NCT00030654) examining the effect of immediate vs. delayed docetaxel chemotherapy with ADT for PSA recurrence after definitive therapy. ADT with or without docetaxel for patients with rising PSA after radical prostatectomy was investigated in a phase 3 trial (XRP6976J_3503, NCT00514917), but this study was terminated after all participants had completed treatment with docetaxel, showing marginal prolonged PFS by combining with docetaxel chemotherapy (19).

\section{CONCLUSION}

The battle between clonal selection and adaption theories in treatment resistance is old, but it is a new debate in cancer biology. In favor of clonal selection theory, up-front docetaxel chemotherapy combined with ADT can almost eradicate androgen-dependent and CRPC cells, and result in prolonged cancer control. In contrast, 
possibly more in favor of adaption theory, up-front docetaxel chemotherapy can exert a superior anticancer effect compared with when it is prescribed after obtaining castration resistance. Thus, although it remains unresolved, the success of the CHAARTED and STAMPEDE trials is a major advance in this field and indicates the superiority of up-front docetaxel chemotherapy.

Thus, up-front docetaxel could be an attractive option for selected patients. However, appropriate selection of patients for up-front chemotherapy would be important since monitoring the efficacy of up-front chemotherapy is almost impossible and toxicity of chemotherapy cannot be ignored. It is important to identify patients who enjoy the benefit of up-front chemotherapy for metastatic hormone-naïve prostate cancer and establish personalized medicine. These aims could be achieved by identifying predictors of poor response to hormonal therapy or good response to chemotherapy, using clinical characteristics or serum/genetic biomarkers.

Evidence that chemotherapy can improve the oncological outcome of definitive therapy for non-metastatic prostate cancer has not been in the process of being obtained. Thus, efforts to extend

\section{REFERENCES}

1. Tannock IF, de Wit R, Berry WR, Horti J, Pluzanska A, Chi KN, et al. Docetaxel plus prednisone or mitoxantrone plus prednisone for advanced prostate cancer. N Engl J Med (2004) 351:1502-12. doi:10.1056/NEJMoa040720

2. Petrylak DP, Tangen CM, Hussain MH, Lara PN Jr, Jones JA, Taplin ME, et al. Docetaxel and estramustine compared with mitoxantrone and prednisone for advanced refractory prostate cancer. N Engl J Med (2004) 351:1513-20. doi:10.1056/NEJMoa041318

3. Shiota M, Yokomizo A, Fujimoto N, Kuruma H, Naito S. Castration-resistant prostate cancer: novel therapeutics pre- or post-taxane administration. Curr Cancer Drug Targets (2013) 13:444-59. doi:10.2174/15680096113139990078

4. Eigl BJ, Eggener SE, Baybik J, Ettinger S, Chi KN, Nelson C, et al. Timing is everything: preclinical evidence supporting simultaneous rather than sequential chemohormonal therapy for prostate cancer. Clin Cancer Res (2005) 11:4905-11. doi:10.1158/1078-0432.CCR-04-2140

5. Fizazi K, Sikes CR, Kim J, Yang J, Martinez LA, Olive MC, et al. High efficacy of docetaxel with and without androgen deprivation and estramustine in preclinical models of advanced prostate cancer. Anticancer Res (2004) 24:2897-903.

6. Shiota M, Kashiwagi E, Yokomizo A, Takeuchi A, Dejima T, Song Y, et al. Interaction between docetaxel resistance and castration resistance in prostate cancer: implications of Twist1, YB-1, and androgen receptor. Prostate (2013) 73:1336-44. doi:10.1002/pros.22681

7. Marín-Aguilera M, Codony-Servat J, Reig Ò, Lozano JJ, Fernández PL, Pereira MV, et al. Epithelial-to-mesenchymal transition mediates docetaxel resistance and high risk of relapse in prostate cancer. Mol Cancer Ther (2014) 13:1270-84. doi:10.1158/1535-7163.MCT-13-0775

8. Puhr M, Hoefer J, Schäfer G, Erb HH, Oh SJ, Klocker H, et al. Epithelial-tomesenchymal transition leads to docetaxel resistance in prostate cancer and is mediated by reduced expression of miR-200c and miR-205. Am J Pathol (2012) 181:2188-201. doi:10.1016/j.ajpath.2012.08.011

9. Gravis G, Fizazi K, Joly F, Oudard S, Priou F, Esterni B, et al. Androgendeprivation therapy alone or with docetaxel in non-castrate metastatic prostate cancer (GETUG-AFU 15): a randomised, open-label, phase 3 trial. Lancet Oncol (2013) 14:149-58. doi:10.1016/S1470-2045(12)70560-0

10. Sweeney CJ, Chen YH, Carducci M, Liu G, Jarrard DF, Eisenberger M, et al. Chemohormonal therapy in metastatic hormone-sensitive prostate cancer. $N$ Engl J Med (2015) 373:737-46. doi:10.1056/NEJMoa1503747

11. James ND, Sydes MR, Mason MD, Clarke NW, Anderson J, Dearnaley DP, et al. Docetaxel and/or zoledronic acid for hormone-naïve prostate cancer: first overall survival results from STAMPEDE (NCT00268476). J Clin Oncol (2015) 33(Suppl):5001. the merit of up-front chemotherapy for metastatic hormonenaïve prostate cancer by applying it to non-metastatic hormonenaive prostate cancer should be maintained. In addition, novel AR-targeting agents abiraterone acetate and enzalutamide have also been investigated in up-front application for metastatic hormone-naïve prostate cancer combined with conventional ADT, as well as non-metastatic hormone-naïve prostate cancer with definitive therapy. If those agents can improve prognosis, head-to-head comparison between up-front chemotherapy and up-front novel AR-targeting agents would be warranted in future, which could lead to major changes in prostate cancer therapy.

\section{AUTHOR CONTRIBUTIONS}

MS wrote the manuscript. AY and ME supervised.

\section{FUNDING}

This work was supported by JSPS KAKENHI Grants (26861273).

12. Fizazi K, Jenkins C, Tannock IF. Should docetaxel be standard of care for patients with metastatic hormone-sensitive prostate cancer? Pro and contra. Ann Oncol (2015) 26:1660-7. doi:10.1093/annonc/mdv245

13. Tucci M, Bertaglia V, Vignani F, Buttigliero C, Fiori C, Porpiglia F, et al. Addition of docetaxel to androgen deprivation therapy for patients with hormone-sensitive metastatic prostate cancer: a systematic review and meta-analysis. Eur Urol (2015). doi:10.1016/j.eururo.2015.09.013

14. Sonpavde G, Bhor M, Hennessy D, Bhowmik D, Shen L, Nicacio L, et al. Sequencing of cabazitaxel and abiraterone acetate after docetaxel in metastatic castration-resistant prostate cancer: treatment patterns and clinical outcomes in multicenter community-based US oncology practices. Clin Genitourin Cancer (2015) 13:309-18. doi:10.1016/j.clgc.2014.12.019

15. de Bono JS, Oudard S, Ozguroglu M, Hansen S, Machiels JP, Kocak I, et al. Prednisone plus cabazitaxel or mitoxantrone for metastatic castration-resistant prostate cancer progressing after docetaxel treatment: a randomised openlabel trial. Lancet (2010) 376:1147-54. doi:10.1016/S0140-6736(10)61389-X

16. Fizazi K, Abrahamsson PA, Ahlgren G, Bellmunt J, Castellano D, Culine $\mathrm{S}$, et al. Achievements and perspectives in prostate cancer phase 3 trials from genitourinary research groups in Europe: introducing the Prostate Cancer Consortium in Europe. Eur Urol (2015) 67:904-12. doi:10.1016/j. eururo.2014.08.076

17. Dorff TB, Flaig TW, Tangen CM, Hussain MH, Swanson GP, Wood DP Jr, et al. Adjuvant androgen deprivation for high-risk prostate cancer after radical prostatectomy: SWOG S9921 study. J Clin Oncol (2011) 29:2040-5. doi:10.1200/JCO.2010.32.2776

18. Cha EK, Eastham JA. Chemotherapy and novel therapeutics before radical prostatectomy for high-risk clinically localized prostate cancer. Urol Oncol (2015) 33:217-25. doi:10.1016/j.urolonc.2014.11.020

19. ClinicalTrials.gov. Available from: https://clinicaltrials.gov/ct2/home

20. Fizazi K, Lesaunier F, Delva R, Gravis G, Rolland F, Priou F, et al. A phase III trial of docetaxel-estramustine in high-risk localised prostate cancer: a planned analysis of response, toxicity and quality of life in the GETUG 12 trial. Eur J Cancer (2012) 48:209-17. doi:10.1016/j.ejca.2011.10.015

21. Fizazi K, Faivre L, Lesaunier F, Delva R, Gravis G, Rolland F, et al. Androgen deprivation therapy plus docetaxel and estramustine versus androgen deprivation therapy alone for high-risk localised prostate cancer (GETUG 12): a phase 3 randomised controlled trial. Lancet Oncol (2015) 16:787-94. doi:10.1016/S1470-2045(15)00011-X

22. Sandler HM, Hu C, Rosenthal SA, Sartor O, Gomella LG, Amin M, et al. A phase III protocol of androgen suppression (AS) and 3DCRT/IMRT versus AS and 3DCRT/IMRT followed by chemotherapy (CT) with docetaxel and prednisone for localized, high-risk prostate cancer (RTOG 0521). J Clin Oncol (2015) 33(Suppl):5002. 
23. Kellokumpu-Lehtinen PL, Hjälm-Eriksson M, Thellenberg-Karlsson C, Åström L, Franzen L, Marttila T, et al. Toxicity in patients receiving adjuvant docetaxel + hormonal treatment after radical radiotherapy for intermediate or high-risk prostate cancer: a preplanned safety report of the SPCG-13 trial. Prostate Cancer Prostatic Dis (2012) 15:303-7. doi:10.1038/pcan.2012.13

Conflict of Interest Statement: Masaki Shiota and Akira Yokomizo have received lecture fees from Janssen Pharma (Masaki Shiota and Akira Yokomizo), Astellas Pharma (Akira Yokomizo), and Sanofi (Masaki Shiota and Akira Yokomizo).
Masatoshi Eto has received honoraria as the lecture moderator from Janssen Pharma, Astellas Pharma, and Sanofi.

Copyright $\odot 2016$ Shiota, Yokomizo and Eto. This is an open-access article distributed under the terms of the Creative Commons Attribution License (CC BY). The use, distribution or reproduction in other forums is permitted, provided the original author(s) or licensor are credited and that the original publication in this journal is cited, in accordance with accepted academic practice. No use, distribution or reproduction is permitted which does not comply with these terms. 